\title{
Older Characters
}

In children's literature circles, it's been common knowledge that children like to read about their own age groups or slightly higher. This pattern is dislodged in a new group of books where the protagonists or dynamic secondary characters are not young; some of these key characters are adults, and some are older adults. From what we can tell, young readers enjoy peeking into the adult world, and as long as the content and themes are appropriate, we suggest that such stories can be powerful additions to various collections.

In addition to presenting engaging stories and information, picture books are a good resource to teach children the importance of listening to and respecting our previous generations. Children who have little or no contact with older adults might find a source of connection in stories. Picture books about older characters also recognise the love and connections that many children share with their grandparents, who in some families are their primary caregivers. This collection of picture books offers wonderful opportunities to increase empathy and heighten interest in reading by following older characters and their storied lives.

Full of caring messages and teachings, many of the picture books here that feature older characters offer important life lessons and models of intergenerational respect. Other titles offer opportunities for readers to observe and learn from adult experiences - not always easy ones. We anticipate that many more titles will emerge in this category over the years to come, and note that a number of titles presenting older characters appear in other chapters, particularly titles with Indigenous languages in addition to English.

These books are popular with young children, but we also see a place for them across all age groups as they might support adults who are learning to read as well as older readers - far beyond the suggested reading ages here whose decoding and comprehension skills are limited due to cognitive and other health challenges, or for being new to the English language.

Where not otherwise indicated, the name of the author(s) appears first under each title, and the illustrator last. 


\section{Carson Crosses Canada}

Linda Bailey

and Kass Reich

Annie Magruder, a white-haired older woman, journeys from the west coast to the east with her dog, Carson, doing justice to iconic Canadian places along the way. With its spry heroine, this book breaks stereotypes about aging while offering information about Canada. Endpapers show

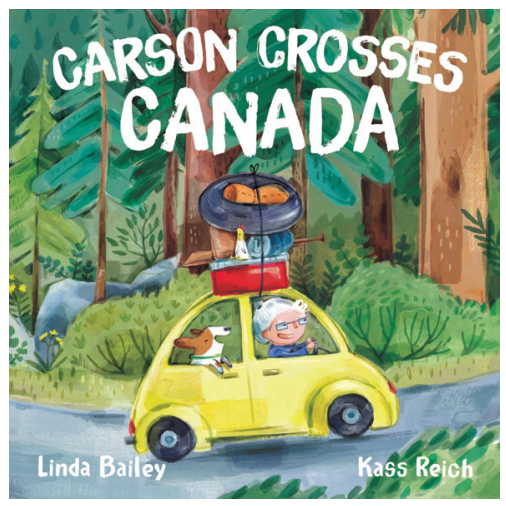
the route across the country as well as what Annie and Carson experience. Kass Reich's hand-painted gouache illustrations, with added digital details, are energetic and fun. For ages $3^{-8}$.

\section{Under the Umbrella}

Catherine Buquet,

Erin Woods (translator)

and Marion Arbona

A man with a stormy heart is out in the rain, rushing grumpily to work. His umbrella blows inside out and lands at the feet of a little boy gazing into a bakery window. The man's internal cloud lifts and he uncharacteristically stops and buys a treat for the

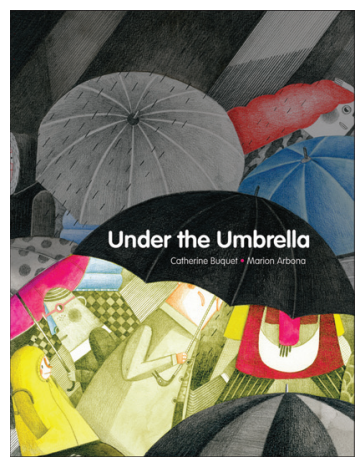
boy, a pastry which is subsequently shared. This gently rhyming story reminds us of the importance of caring for others and reassures us that bright moments can be found even on dark days. For ages 4-8.

\section{The Pink Umbrella}

Amélie Callot,

\section{Lara Hinchberger (translator) and Geneviève Godbout}

Adele, a café owner, usually sparkles except when it's raining. Lucas, the grocer, sends her thoughtful gifts to brighten the rainy days. This is a story about compassion and the quiet power of love. Geneviève Godbout's illustrations were rendered in pastels and coloured pencils and the text is hand-lettered. For ages 6-9.

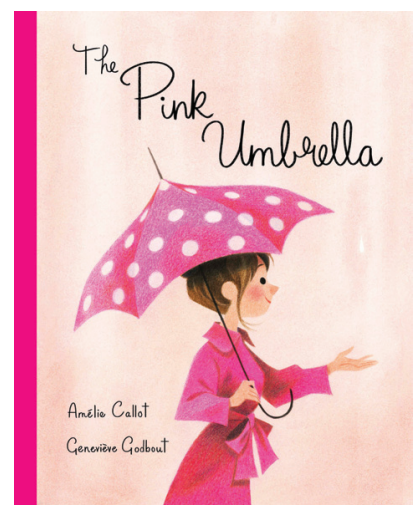




\section{Bon Voyage, Mister Rodriguez}

Christiane Duchesne

and François Thisdale

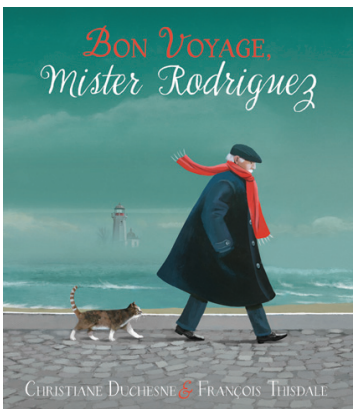

A group of older children study Mr. Rodriguez as he takes his daily walk. His activities become increasingly fantastical until one day, he appears to fly away and they never see him again. What reads as a quirky story can also be digested as an allegory of death. François Thisdale's spectacular images are created with acrylic and digital media. For ages 5-9.

\section{The Eleventh Hour}

Jacques Goldstyn

Jim and Jules are childhood friends who enlist in World War I. As young adults, they fight together and endure many hardships, but in the end Jim dies in his friend's arms. The story follows Jules as he returns home and struggles to find his way as a watchmaker, his characterisation reflecting the invisible injuries of war. Author Jacques Goldstyn is also a political cartoonist, and his watercolour and pencil illustrations reflect his signature style. For ages $7-12+$.

\section{The Vimy Oaks: A Journey to Peace \\ Linda Granfield \\ and Brian Deines}

Leslie Miller, a real Canadian soldier in World War I, mails a handful of acorns home from France. Years later, a boy and his family tour the Canadian farm where shady oak trees stand in a line, trees grown and tended by Lieutenant Miller once he returned from the war. Descendants of these trees were sent to the Vimy Ridge battlefield to repatriate the oaks that were lost, as well as distributed across Canada. Many generations have enjoyed these trees and the memories they convey about peace, justice and remembrance. Brian Deines' rich oil-oncanvas illustrations, alongside many photographs, illustrate this title. For ages 8-adult.

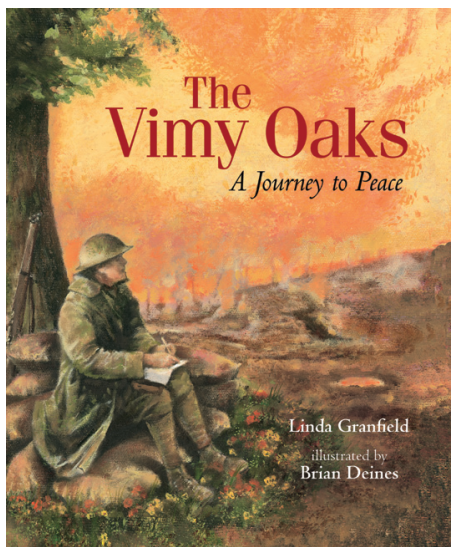




\section{I'm Glad That You're Happy \\ Nahid Kazemi}

This is a story about two plants. The florist who plants them in one pot tells the bigger one to look after the smaller one. A painter takes them home and eventually divides them, finally putting them in his garden where they grow into trees. This is a story about accepting growth and change. Nahid Kazemi's illustrations include pastel, colour pencil, and collage. For ages 4-8.

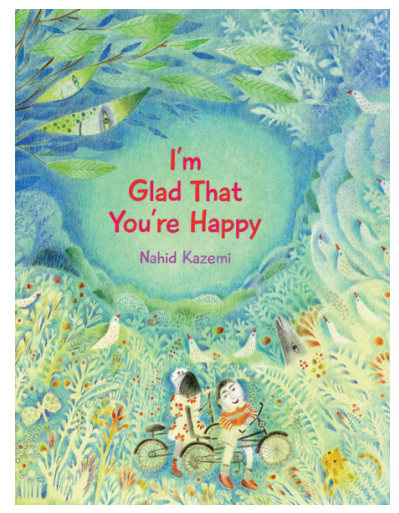

\section{Before You Were Born}

Deborah Kerbel

and Suzanne Del Rizzo

Through the changing seasons, a couple awaits their baby while wild animals nearby welcome their own young. The rhyming text describes the adults' emotions and dreams for their child. Suzanne Del Rizzo's stunning artwork is a combination of polymer clay and acrylic wash.

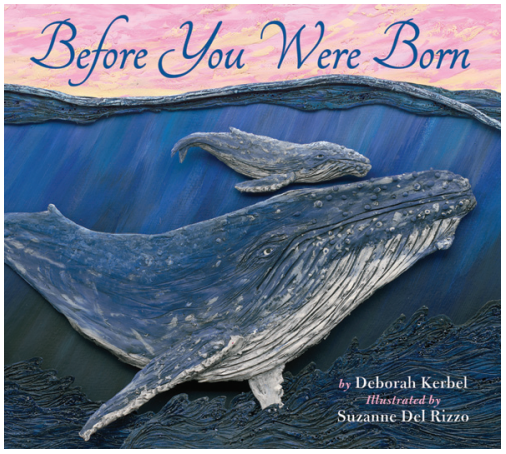

For ages $3-7$.

\section{Threads}

Torill Kove

This book celebrates the beauty and complexity of parental love. A mother is symbolically threaded to a child and then encourages opportunity and eventually independence. This title is adapted from a National Film Board animated short film of the same name. For ages 7-adult.

\section{My Cat Looks Like My Dad \\ Thao Lam}

This original story is essentially a list of the various ways the narrator's dad resembles their cat. A surprising twist at the end discloses that the narrator is actually a bird. The message of this book is that family is what you make it. The retro style collage artwork was created using patterned paper. For ages $3-8$. 


\section{Uncle Holland \\ JonArno Lawson \\ and Natalie Nelson}

Holland is always getting into trouble. After continued stealing, he is offered a choice - either go to jail or join the army. He chooses the latter and is stationed in the south, where he develops an interest in fishes and becomes an artist! This story is loosely based

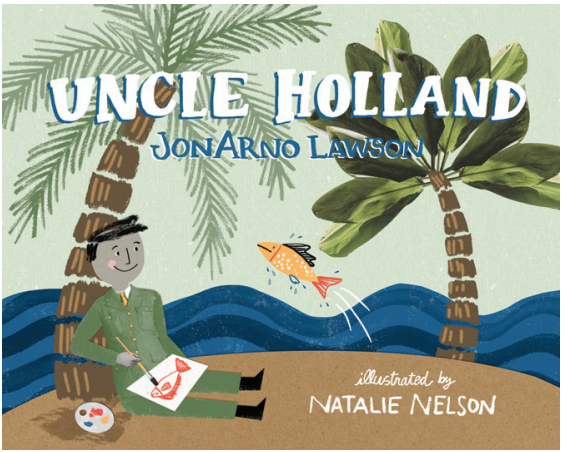
on the life of JonArno's uncle. Natalie Nelson's illustrations are digital collage incorporating found photography and ink drawings. For ages $6-9$.

\section{Grandmother's Visit \\ Betty Quan \\ and Carmen Mok}

Grandmother lives with Grace's family and teaches her many things, such as how to cook rice. She also tells her stories about growing up in China. As Grandmother grows older, things change. One day her room is empty. In this poignant tale, Grace realises that even though Grandmother has passed away, all of

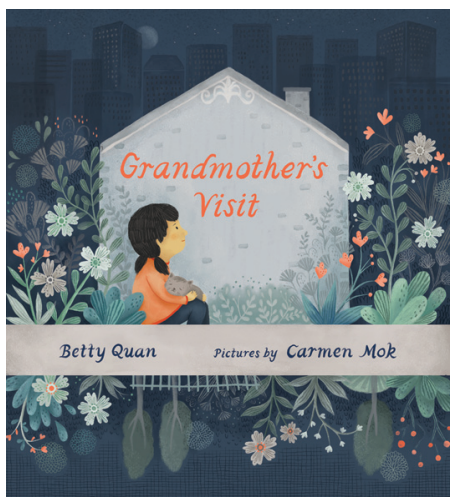
her teachings and memories remain. Carmen Mok's digital paintings capture love, sadness and resiliency in this sensitive and tender story. For ages $5^{-8+}$.

\section{Mr. Crum's Potato Predicament \\ Anne Renaud \\ and Felicita Sala}

Diners flock to sample Cook Crum's fare until a demanding customer prompts him to slice the potatoes thinner and thinner until they are crispy thin! This story is loosely based on the life of George Crum, possible inventor of the potato chip. Felicita Sala's watercolour and coloured pencil images are deliciously executed in a feast for the eyes. For ages $4-8$. 
The Promise Basket

Bill Richardson

and Slavka Kolesar

For each celebration with her daughter, a mother wraps up a pretty stone and puts it in the promise basket along with a poem. When her granddaughter is born, the mother gives her daughter the promise basket and the daughter knows it is her turn to write promises to her own daughter. Slavka Kolesar's illustrations are in coloured pencil, graphite, watercolour and gouache. For ages $5^{-9}$.

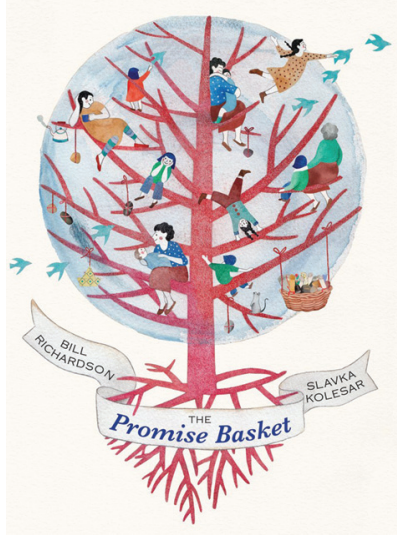

Tricky

Kari Rust

The Duke and his faithful dog, Tricky, spend their days making people miserable. One day, Tricky realises what they are doing is wrong, and changes his course, although it means going their separate ways. This story shows that an old dog can indeed learn new tricks! For ages $5^{-9}$.

\section{A Plan for Pops}

\section{Heather Smith}

and Brooke Kerrigan

Every Saturday Lou visits Grandad and Pops. After lots of experience building inventions, Lou decides to make something to help Pops, whose mobility has changed and who is depressed. Brooke Kerrigan has beautifully rendered this non-traditional family structure using an iPad Pro, with the addition of scanned textures, traditional watercolour washes, and paper collage. For ages

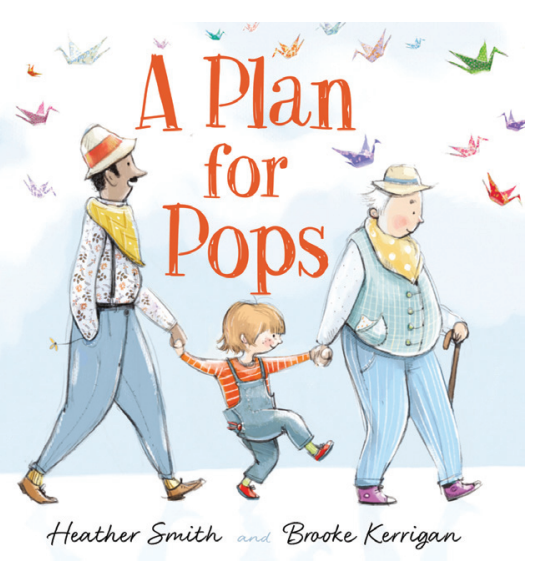
$4-8$. 
Eighteen Wheels and a Dozen Roses Caroline Stellings

Dog characters Matt and Ben demonstrate adult human characteristics as they operate a garage and fix old cars. Each time Matt thinks the finished product might just be for him, he finds someone who needs it more. In the end, someone he has helped does a nice thing for him in return. The watercolour and pen-andink illustrations for this karmic tale are soft and uplifting. For ages $5^{-8}$.

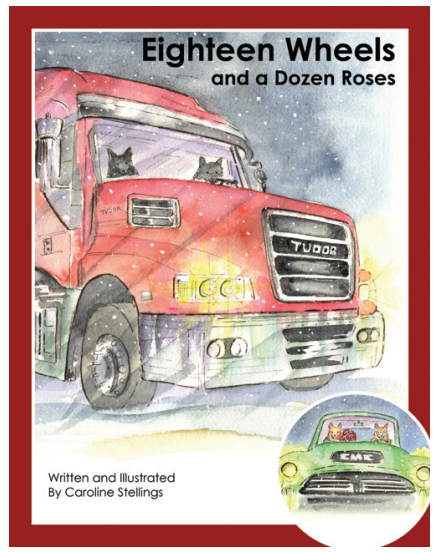

\section{Nimoshom and His Bus}

Penny M. Thomas

and Karen Hibbard

This book is about Nimoshom, a school bus driver. His name means "grandfather" in Cree, and as he drives the bus, he teaches his school-aged passengers and readers of the book - a number of

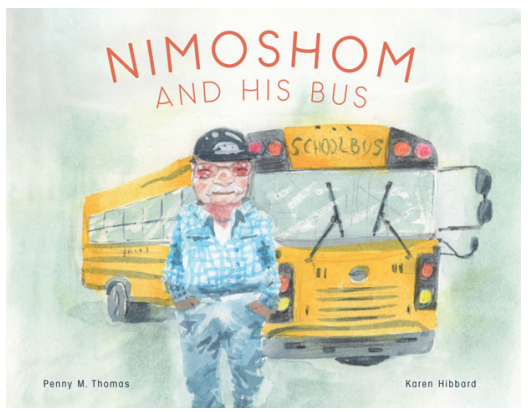
Cree words. This book does an excellent job of displaying the powerful connection between elders and youth. Penny M. Thomas is of Cree-Ojibway background and she has included a Cree word list, with translations, at the end of the book. Karen Hibbard's engaging watercolour and pastel illustrations extend the story nicely. For ages 4-8.

\section{The Heart's Song}

Gilles Tibo

and Irene Luxbacher

Miss Matilda sits in the park and uses her special tools to fix the children's broken toys. Sometimes she sings to those who are sad. When Miss Matilda's beloved canary dies, the children bring her messages of love in return. Irene Luxbacher's illustrations were created with acrylics, graphite, charcoal, and found papers, and assembled digitally. This is a story about

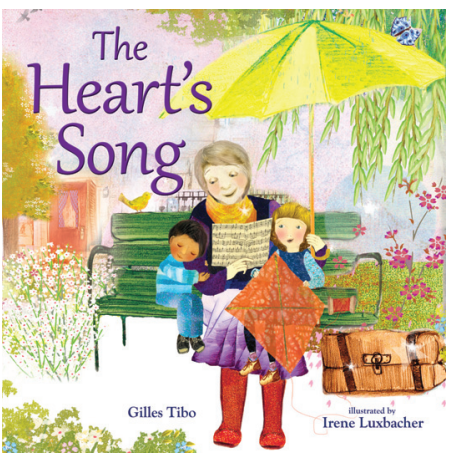
friendship and compassion. For ages 4-8. 


\section{The Outlaw}

Nancy Vo

An outlaw known for his misdeeds finally leaves town. Many seasons later, a stranger appears and begins helping out. He is working on the train platform when somebody suddenly recognises him. A young boy sticks up for him and the outlaw is allowed to stay, where he continues to make

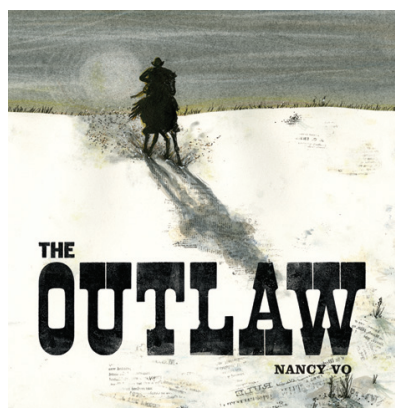
amends in this story about redemption. In strikingly original images, Nancy Vo works with ink, watercolour and newsprint transfer, using newspaper clippings and fabric patterns from the late 19th century. The text is set in Clarendon, common on "wanted" posters. For ages $5^{-9+}$

\section{The Ranger}

Nancy Vo

A ranger named Annie encounters a fox in need, tends to its wounds, and feeds it. A few days later, it is the ranger who needs help, and the fox steps in. The illustrations, ink, watercolour, and acetone transfer depict Annie as a young adult who is comfortable on her own but who benefits from having a companion. For ages $5^{-9+}$.

\section{Crackerjack Jack}

Bowman Wilker

and Marie-Ève Tremblay

This rollicking story, told through rhyme and varying font size, is about a bank robber whose accomplice is a duck. Jack is caught while the duck makes off with the money to live a life of luxury. For ages $4-8$.

\section{Bibliography}

*In the spirit of the recommendations of the Truth and Reconciliation Commission, an asterisk appears beside works created by Indigenous writers or artists.

Bailey, Linda (illustrated by Kass Reich) (2017). Carson Crosses Canada. Toronto, ON: Tundra Books/Penguin Random House. 
Buquet, Catherine (illustrated by Marion Arbona, translated by Erin Woods) (2017). Under the Umbrella. Toronto, ON: Pajama Press.

Callot, Amélie (illustrated by Geneviève Godbout) (2018). The Pink Umbrella. Toronto, ON: Tundra Books/Penguin Random House.

Duchesne, Christiane (illustrated by François Thisdale) (2019). Bon Voyage, Mister Rodriguez. Toronto, ON: Pajama Press.

Goldstyn, Jacques (2018). The Eleventh Hour. Toronto, ON: Owlkids Books.

Granfield, Linda (illustrated by Brian Deines) (2017). The Vimy Oaks: A Journey to Peace. Toronto, ON: North Winds Press/Scholastic Canada.

Kazemi, Nahid (2018). I'm Glad That You're Happy. Toronto, ON: Groundwood Books/ House of Anansi Press.

Kerbel, Deborah (illustrated by Suzanne Del Rizzo) (2019). Before You Were Born. Toronto, ON: Pajama Press.

Kove, Torill (2017). Threads. Richmond Hill, ON: Firefly Books.

Lam, Thao (2019). My Cat Looks Like My Dad. Toronto, ON: Owlkids Books.

Lawson, JonArno (illustrated by Natalie Nelson) (2017). Uncle Holland. Toronto, ON: Groundwood Books/House of Anansi Press.

Quan, Betty (illustrated by Carmen Mok) (2018). Grandmother's Visit. Toronto, ON: Groundwood Books/House of Anansi Press.

Renaud, Anne (illustrated by Felicita Sala) (2017). Mr. Crum's Potato Predicament. Toronto, ON: Kids Can Press.

Richardson, Bill (illustrated by Slavka Kolesar) (2019). The Promise Basket. Toronto, ON: Groundwood Books/House of Anansi Press.

Rust, Kari (2017). Tricky. Toronto, ON: Owlkids Books.

Smith, Heather (illustrated by Brooke Kerrigan) (2019). A Plan for Pops. Victoria, BC: Orca Book Publishers.

Stellings, Caroline (2017). Eighteen Wheels and a Dozen Roses. Winnipeg, MB: Peanut Butter Press.

*Thomas, Penny M. (illustrated by Karen Hibbard) (2017). Nimoshom and His Bus. Winnipeg, MB: Highwater Press.

Tibo, Gilles (illustrated by Irene Luxbacher) (2017). The Heart's Song. Toronto, OM: Scholastic Canada.

Vo, Nancy (2018). The Outlaw. Toronto, ON: Groundwood Books/House of Anansi Press.

Vo, Nancy (2019). The Ranger. Toronto, ON: Groundwood Books/ House of Anansi Press.

Wilker, Bowman (illustrated by Marie-Ève Tremblay) (2018). CrackerjackJack. Toronto, ON: Owlkids Books. 